\title{
EVALUATING CRITERIA FOR DP VESSELS
}

\author{
Jerzy Herdzik \\ Gdynia Maritime University, Marine Power Plant Department \\ Morska Street 81-87, 81-225 Gdynia, Poland \\ tel.:+4858 6901430, fax: +48586901399 \\ e-mail: georgher@am.gdynia.pl
}

\begin{abstract}
The paper presents the evaluating criteria for DP vessels. A few persons tried to give a simple tool for comparing the station keeping capability between different ships. It was started in the seventies when most vessels claiming to have a $D P$ system would be carried away by the current only (the limit was 1.5 up to 2 knots). Mainly DNV and ABS, next IMO prepared the calculating methods for DP system evaluation during the design process to receive the DP class 1,2 or 3. The regulations may help but it's still only rough estimate. One of them is the most popular. It is the capability plot presenting at preliminary the polar diagram with number envelops, showing the vessel's capability to keep position or heading with a certain combination of thrusters in operation. The number, type, total power (or thrust) and location of thrusters are vital for estimating the DP capability from the propulsion system. The other equipment is only accessories assisting the DP system. At the end the sea trial may check and confirm the DP class of the vessel. The real capability for station keeping will be verified during normal operation, essentially during emergency situations like electric network faults, propulsion system failure up to damages and fire. It is needed some indexes or parameters during the design process to avoid serious faults. The paper is a probe of becoming familiar with chosen criteria.
\end{abstract}

Keywords: DP systems, station keeping, evaluating criteria, estimation of DP systems

\section{Introduction}

At present the basic method of confirming at preliminary the station keeping capability is the capability plot presenting as a polar diagram with a number of envelops, depicting the vessel's capability to keep position in a certain environment with a certain combination of thrusters [1,2]. An example is presented on Fig. 1.

The capability plot is often set against a scale of increasing wind speed (to a determinate maximum level) with a fixed current speed and a fixed determinate wave height. Normally all three environmental forces are acting from the same direction and there is a relation between wind speed and the wave height (the relationship depends on sea area - known special spectrum of waves). It is a necessary to carry out various calculations taking into account:

- wind forces acting from various directions $\left(0^{\circ}-\right.$ bow, $180^{\circ}-$ aft $)$,

- wave drift forces acting from various directions,

- current drag forces acting from various directions,

- propeller, rudder and thruster efficiency in various positions and their interaction with hull and between them [10].

The wind speed is the most easily measured environmental force. The wave height and current speed often require the measured equipment located outside the vessel.

\section{Propulsion system - the basic system in DP capability}

The DP capability depends among other elements on propulsion system with required redundancy. The propulsion system for transit is not very useful for the station keeping and vice versa $[4,8]$. The main design task of DP propulsion system is to give the possibility of generating 


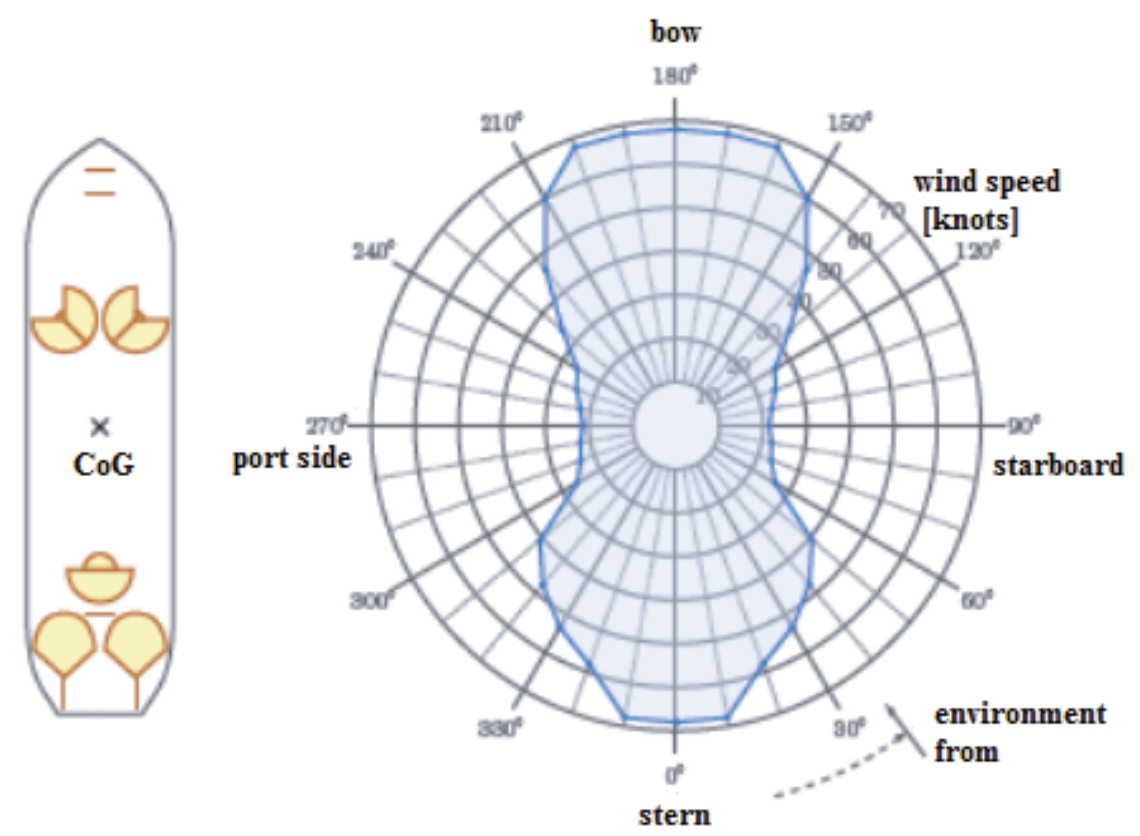

Fig. 1. Sample capability plot - all 6 thrusters' active, possible 100\% power [13]

the demanded forces and moment from thrusters under conditions:

- the minimum of total thruster power allows the minimum of fuel consumption,

- the minimum number of thrusters (with the required redundancy) located as far as possible from the centre of the vessel gravity,

- the thrust ought to be available in the angle of $360^{\circ}$ (all around),

- find the optimal thruster angle and thruster force from thrusters equal to commanded forces (surge, sway) and moment (yaw) (Fig. 2).

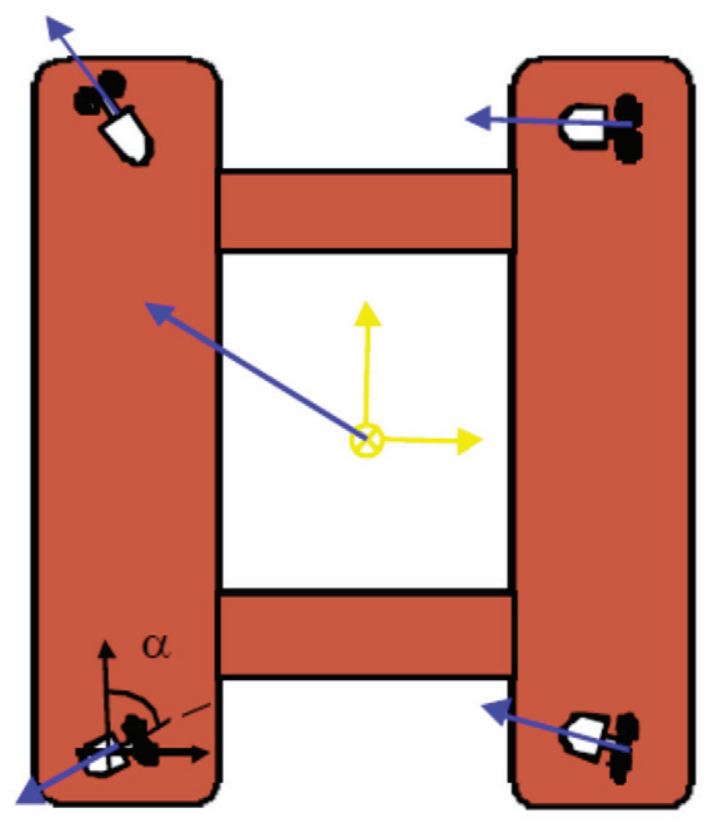

Fig. 2. Thrust allocation of four thrusters for commanded force

The simple parameters (indexes) describing the DP capability are needed. It allows for the preliminary assessment the vessel's propulsion system. The proper design of propulsion system is the first step for the selection of the DP accessories. 


\section{Examples of evaluating criteria of DP systems}

The first criteria for DP vessels has been proposed by Holger Rokeberg (DNV) in seventies as the ERN (Environmental Regularity Number). It was a calculation method based only on lateral forces: wind, current (up to 1.5 knot) and waves coming in on the beam.

The ERN consist of three group of digits:

- the first group - indicates the chance of the vessel to keeping position at a certain location in the North Sea when all systems are working,

- the second group - indicates the chance to keep position if the most ineffective thruster fails,

- the third group - indicates the chance to keep position if the most effective thruster fails.

The best ERN was $(99,99,99)$ and it was an argument for oil companies in their tender specifications to require the numbers for DP vessels.

The PCR (Lloyd's Register Performance Capability Rating) was next one in the eighties. The PCR consists of two digit groups:

- the first digit group - indicates the time the vessel can keep position providing all systems are working,

- the second digit group - indicates the time the vessel can keep position if the most effective thruster fails.

Calculation in PCR consider thruster efficiency, current speed (up to 2 knots) and restoring forces of $20 \%$ of the total forces (it means that the actual thruster force used in the calculation is less than $80 \%$ of nominal thrust).

The Capability Plots - were prepared by DP system suppliers and other organizations. The results can vary considerable for the same vessel depending on the calculating method. The main differences having an effect on results were:

- the different ways for the calculating the wave drift forces;

- the different ways of estimating the thruster efficiency.

Current forces and wind forces may be simply calculated by using simple formulas and the relevant drag coefficient. Model tests are the way for to obtain reliable values.

Wave drift forces can be obtained from model tests. The wave height is seen as a linear function of the wind speed what is a true for certain areas (North Sea or Mexican Gulf). When calculating the drift forces they are very dependent upon the wave period. The short waves give higher forces than long waves with the same wave height (the wave spectrum on selected area is needful) [10].

Thruster efficiency is one of the most difficult variables to get into consideration. Many factors have an influence on thruster efficiency like: the shape of hull, the distance between thrusters, the diameter of thrusters etc. The best method is:

- full scale tests,

- model tests.

The thrusters are often tested one by one and all together. The total thrust is less than the sum of each of them $[6,7]$.

The "Transverse Speed Criteria" is simple to measure and can be done in the following conditions:

- $100 \%$ power and thruster is available,

- $50 \%$ power and/or thrust is available.

The other parameters are as follows: the wind driven current is up to $1.5 \mathrm{knots}$, the vessel should sail minimum 2 knots transverse, the heading variation during this exercise should be below $\pm 3^{\circ}$. An example on capability plot is shown on Fig. 3.

The "transverse speed criteria" is very simple indication of DP system capability between different vessels, eliminates the discussions because the thruster efficiency and their interaction should be take into consideration. 


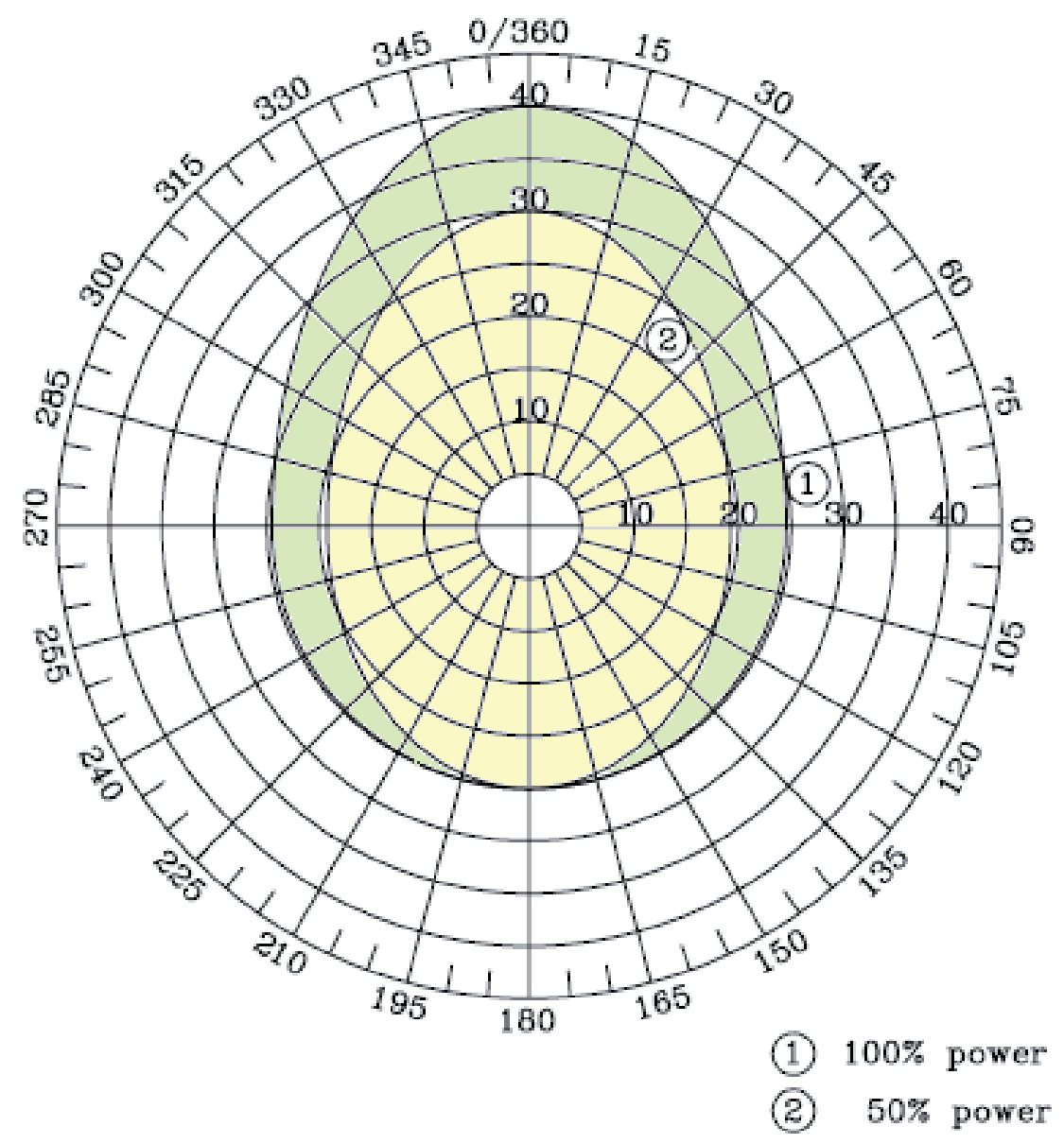

Fig. 3. Capability plot for "transverse speed criteria" [10]

\section{The necessity of definition the simple parameters of DP systems}

As it has been seemed the transverse speed is a simple parameter to evaluate the vessel DP capability. The common current speed is below 1.5 knots with some exceptions. The minimum transverse speed of vessel ought to be 2 knots, a little over the current speed and consequently the vessel drift. The drift forces are the function of wave period and wind speed and current speed. The dependence was shown on Fig. 4. The maximum drift force for vessel always occurs in direction of $90^{\circ}$, it means in direction perpendicularly to the vessel's side.

The next parameter similar to above presented one is the thrust to transverse area indicator (TTTI) presented by equation (1).

$$
\mathrm{TTTI}=\frac{T}{L \cdot D}
$$

where:

$T$ - total thrust (the summa of all thrusters in operation),

$L$ - the vessel's length on water level,

$D$ - the vessel's draught.

The minimum TTTI ought to be about $2 \mathrm{kN} / \mathrm{m}^{2}$ to receive the minimum 2 knots transverse speed. Practical application of transverse thrusters with a fixed propeller shaft installed 90 degrees to the longitudinal axis of the vessel is the easy way to reach 2 knots of transverse speed. They are used to provide side thrust. They are often inactive during transit operation. Transverse thrusters include tunnel thrusters, and retractable thrusters operating under the hull of the vessel. The tunnel openings can cause a noticeable increase of the resistance of the vessel at service speed. 


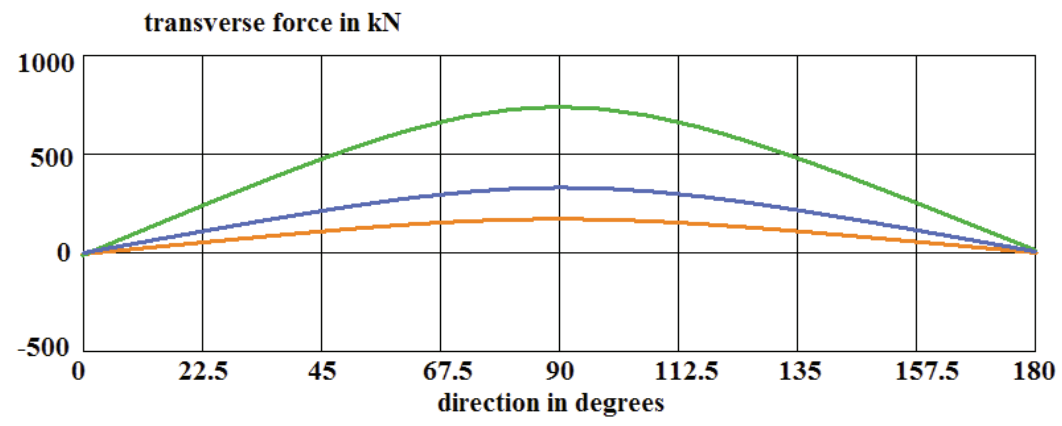

Fig. 4. Example of wave drift forces as a function of wave period. Wave periods are from top to bottom $4 s, 8 s, 12 s$, wind force and current force is from speed 1.5 knots [10]

The indicator of propulsion plant configuration $\left(R_{i j}\right)$ has been the proposition [11] for evaluating method of the DP operation possibility. The equation (2) presents the DP capability taking into the account chosen parameters of propulsion system and chosen weighting indexes.

$$
R_{i j}=\frac{M_{i} \cdot W_{j}+E_{i} \cdot W_{j}+B_{i} \cdot W_{j}+P_{i} \cdot W_{j}+N_{i} \cdot W_{j}+D_{i} \cdot W_{j}+T_{i} \cdot W_{j}}{\sum W_{j}},
$$

where:

$R_{i j}$ - the evaluating indicator of marine power plant propulsion system type " $\mathrm{j}$ ",

$M_{i}$ - etc., the index of chosen parameter of the propulsion plant [11],

$W_{j}$ - the summa of chosen weighting indexes of the chosen vessel [11].

The mentioned indicator may have a number from 1.0 up to 6.0. Approximately the vessels with DP class 3 ought to have the indicator above the number $5.5[3,11]$. The indicator of propulsion plant configuration only tells about the DP capability from the configuration as the point of view $[9,11]$. If it is a small number it means that the DP capability will be very week even if the other additional DP aided system is very sophisticated and expanded.

\section{Final remarks}

A propulsion system applied for dynamic positioning of vessels must be able to generate counter forces against environmental forces as well as forces resulting from drag of a deployed array, pipes, risers etc. It is preferred that the propulsion systems or devices must have the ability to generate thrust in full 360 degrees [5]. The evaluating criteria for DP vessels are the simple way for showing the DP capability only by a few number. This is not a full evaluation but an estimation close to the future full calculations and sea trials. On the other hand there are three basic failure modes of loss of position, namely drive-off, drift-off and force-off [12]. Proposed the resistance to loss of position is an index similar to DP capability indexes because the resistance depends mainly on the propulsion system reliability. The last mode "force-off" happens due to sudden change in environmental conditions when the thruster forces are insufficient to keep the vessel position.

The final remark is that the simple evaluating criteria for DP vessels are needed for showing the DP capability.

\section{References}

[1] A Guide to DP Electrical Power and Control Systems, IMCA M206, 2010, www.imcaint.com.

[2] Dynamic Positioning Systems, Rules for Classification of Ships, part 6, chapter 7, DNV, 2011. 
[3] Pipelaying Vessel Solitaire, Electrical Propulsion System 10kV Supply and Distribution System, SAM Electronics GmbH, Hamburg 2011.

[4] Herdzik, J., Problems of propulsion arrangement choice of multi-mode ships, Journal of KONES, Vol. 17, No. 2, pp. 129-135, Warsaw 2010.

[5] Herdzik, J., Problemy utrzymania gotowości eksploatacyjnej jednostek pływajacych z napędem pędnikami aktywnymi, Logistyka, Nr 2, Pos. 27, pp. 1619-1624, 2010.

[6] Herdzik, J., Application possibilities of electric driven propulsion of multi-mode ships, Journal of KONES, Vol. 17, No. 1, pp. 163-168, Warsaw 2010.

[7] Herdzik, J., Possibilities of Improving Safety and Reliability of Ship Propulsion System During DP Operation, Journal of KONES, Vol. 19, No. 2, pp. 219-226, Warsaw 2012.

[8] Herdzik, J., Challenges of Ship Propulsion Systems During DP Operations, Journal of KONES, Vol. 19, No. 2, pp. 211-218, Warsaw 2012.

[9] Herdzik, J., Verifications of Thrusters Number and Orientation in Ship's Dynamic Positioning Systems, The International Journal on Marine Navigation and Safety of Sea Transportation, June 2013.

[10] Ubisch, von B., Station Keeping Criteria for Dynamically Positioned Ships, Dynamic Positioning Conference, Houston 2004.

[11] Herdzik, J., Metoda szacowania wymagań stawianych okrętowym układom energetycznym, Logistyka, Nr 3, Pos. 94, pp. 891-898, 2011.

[12] Verhoeven, H., et al., Safety of Dynamic positioning Operation on Mobile Offshore Drilling Units, DP Conference, Houston 2004.

[13] Guide to Dynamic Positioning of Vessels, ALSTOM 2000. 